\title{
Factors associated with elderly depression among rural Bangladeshi individuals
}

\author{
Jui Das ${ }^{1}$, Fahmida Dil Farzana ${ }^{1}$, Farzana Ferdous ${ }^{1}$, Shahnawaz Ahmed ${ }^{1}$, Sarah Tegenfeldt ${ }^{1}$, \\ Repon Chandra Paul ${ }^{1}$, Mohammod Jobayer Chisti ${ }^{1}$, Abu Syed Golam Faruque ${ }^{1}$, \\ Sumon Kumar Das ${ }^{1,2, *}$ \\ ${ }^{1}$ Centre for Nutrition and Food Security, International Centre for Diarrhoeal Disease Research, Bangladesh, Shaheed Tajuddin Ahmed \\ Sarani, Mohakhali, Bangladesh \\ ${ }^{2}$ School of Population Health, The University of Queensland, Herston Rd, Herston, QLD 4006, Australia
}

\section{Email address:}

jui_das26@yahoo.com (J. Das), fahmidaf@icddrb.org (F. D. Farzana), farzanaf@icddrb.org (F. Ferdous), shahnawz@icddrb.org (S. Ahmed), sarah.tegenfeldt@gmail.com (S. Tegenfeldt), repon@icddrb.org (R. C. Paul), chisti@icddrb.org (M. J. Chisti), gfaruque@icddrb.org (A. S. G. Faruque), sumon@icddrb.org (S. K. Das)

\section{To cite this article:}

Jui Das, Fahmida Dil Farzana, Farzana Ferdous, Shahnawaz Ahmed, Sarah Tegenfeldt, Repon Chandra Paul, Mohammod Jobayer Chisti, Abu Syed Golam Faruque, Sumon Kumar Das. Factors Associated with Elderly Depression among Rural Bangladeshi Individuals. American Journal of Psychiatry and Neuroscience. Vol. 2, No. 1, 2014, pp. 1-7. doi: 10.11648/j.ajpn.20140201.11

\begin{abstract}
Background: Depression is a chronic disorder, which often remains undiagnosed. There is a gross lack of evidence-based information about depressive illnesses among adult individuals from rural Bangladesh. Objective: The present study aimed to determine the factors that are associated with depressive illness but remain undiagnosed among rural healthy adult individuals. Methodology: A cross-sectional study was conducted in the Demographic Surveillance System area of rural Mirzapur sub-district, during April to September 2010. A total of 130 apparently healthy individuals [no history of hypertension, cardiovascular diseases, hepatic (serum alanine transaminase; ALT) or renal (serum creatinine) dysfunction; diabetic mellitus (fasting blood sugar)] aged 40 years and above were randomly selected from the DSS database. Level of depression was assessed using 30-item Geriatric Depression Scale. Results: Forty-two percent of the healthy participants were found to have mild depression, $17 \%$ were severely depressed. In multivariate analysis, females had a 2.79 [95\% CI-0.94-8.26] times higher risk for depression compared to males. Healthy elderly individuals ( $\geq 60$ years) had a 2.79 [0.94-8.33] times higher risk for depression compared to their middle-aged counterparts (40-59 years). Furthermore, individuals who consumed a vegetable-based diet were at 2.47 [0.85-7.15] times higher risk for depression; individuals with low monthly income were at 2.57 [0.94-7.01] times higher, and those with poor wealth index were 1.55 [1.07-2.25] times more likely to suffer from depression compared to their counterparts after adjusting for vitamin B12, folic acid, ALT, and blood hemoglobin. Conclusion: Healthy elderly individuals from rural Bangladesh were more depressed than middle-aged adults; and females with poor socio-economic status were at higher risk for depression than males.
\end{abstract}

Keywords: Bangladesh, Depression, Elderly, Healthy, Rural

\section{Introduction}

Depression is a combination of feelings including: sadness, loneliness, irritability, worthlessness, hopelessness, agitation, and guilt, accompanied by an array of physical symptoms [1]. Depression appears as a serious public health concern in both developed and developing countries [2]. Although individuals irrespective of age, sex, and socio cultural background often suffer from varying levels of depressive illnesses; among the elderly (60 years and above) it is the most common psychiatric disorder [3-8]. It affects approximately 121 million elderly people worldwide; a leading cause of disability and the fourth leading contributor to the global burden of disease [9]. However, depression is often difficult to diagnose [5].

Globally, the proportion of elderly individuals is expected to become more than double in the next 40 years, going from 6.9 billion to 16.4 billion between 2000 and 2050 [10]. Though, much of the elderly population lives in developed countries, it has been estimated that about $60 \%$ of the 580 million elderly in the world live in developing 
countries, and by 2020 that number is expected to increase to $70 \%$ of the total elderly population [10]. Bangladesh, with a high population density and an increasing number of elderly individuals, may experience many of these mental health problems among the elderly population [11].

In addition to lack of social support and networks, elderly often suffer from different chronic diseases [12, 13]. Due to concomitant poverty, elderly individuals often consume foods inadequate in vitamins and minerals. These such deficiencies often make them more vulnerable to depressive disorders [14]. Some micronutrients, for example folate and vitamin B12, have important regulatory effects on neurological functions and the absence of them in diet contributes to the pathology of depression [15-17]. However, there is lack of evidence based information about depressive illnesses in elderly Bangladeshi individuals, especially in the rural community [18]. Thus, this study aimed to determine the proportion of apparently healthy elderly people suffering from depression in rural Bangladesh and the factors associated with depression; then compare those findings with that of healthy adult residents from the same rural community.

\section{Materials and Methods}

\subsection{Study Site}

The study participants were selected from a rural community of Mirzapur, a sub-district under Tangail, about 40 miles northwest of Dhaka, the capital city of Bangladesh. The International Centre for Diarrhoeal Disease Research, Bangladesh (icddr,b) has established a Demographic Surveillance System (DSS) at this field site. About $10 \%$ of the DSS population is aged 60 years or more. A tertiary level hospital, popularly known as Kumudini Women's Medical College and Hospital (KWMCH) with 750 beds, is located at the middle of the DSS area.

\subsection{Study Design, Selection and Sample Size of Study Participants}

This study was conducted following a cross-sectional design from April to September 2010. However, a casecontrol design was considered during data analysis. A total of 250 individuals aged 40 years and above were randomly selected from the DSS database and screened at household level to determine their apparently healthy status by administering a field-tested brief questionnaire. Individuals with previous or recent history of hypertension, cardiovascular disease, diabetes, cerebrovascular disorder, hepatic or renal dysfunction, abnormal bowel habit, and unwilling to participate were excluded as study participants. Thus, a total of 130 apparently healthy adult individuals were included into the study; of them, 34\% $(n=44)$ were aged 60 years or more. These people were categorized as elderly according to WHO definition and literature published elsewhere [19].; and the rest were aged 40-59 years
We used a structured questionnaire and all of them were invited to participate in the study. Upon arrival in the $\mathrm{KWMCH}$, after giving voluntary written consent, they were included into the study. After performing physical examination and measuring blood pressure, individuals' fasting blood sugar was assessed by glucometer (ACCUCHEK, Active, Roche) to exclude diabetes mellitus. Information on basic socio-demographic indicators was collected by administering a structured field-tested questioner to the participants. All the study individuals were finally enrolled after confirming that they had optimal hepatic (serum alanine transaminase; ALT) or renal (serum creatinine) functions; and free from diabetes mellitus (fasting blood sugar).

\subsection{Geriatric Depression Scale}

We employed the Geriatric Depression Scale (GDS) to assess depression. It is a 30 -item scale widely used with higher sensitivity (the ability of a test to detect the proportion of individuals that are known to have the disease) and specificity (test ability to identify negative results) compared to other scales [2, 20-22]. The scale has been indicated to be very straightforward, time effective, and easily deliverable, with findings of assessment of depression easy to record. The scale includes 30 selfreported questions and responses, each having a yes or no answer. The answers were then recorded following standard guidelines. Each question bears a pre-selected score as 1 or 0 for their corresponding answer. Thus if the participant responded "yes" for a particular question then 1 was coded in the designated box, otherwise (if responded "no") 0 was coded, and vice versa. Approximately 10 minutes were required to complete the GDS. Among the 30 responses, 20 were positive responses (yes $=1$ ), and the rest were negatively scored answers $($ no=1). These endorsed items were then cumulated and individuals were classified as depressed or non-depressed. When scores ranged between 10 and 19, individuals were considered to have mild depression. Scores of 20 or higher were considered severely depressed, those less than 10 had been assessed as normal.

\subsection{Anthropometric Measurement and Blood Sampling}

Height and weight of all the participants were measured and Body Mass Index (BMI) was calculated by dividing body weight expressed as $\mathrm{kg}$ by the square of height in meters $\left(\mathrm{kg} / \mathrm{m}^{2}\right)$. Blood pressure was measured by sphygmomanometer. Five milliliters $(5.0 \mathrm{ml})$ of venous blood was collected. For hemoglobin estimation, $0.5 \mathrm{ml}$ of blood was put into an Eppendorf tube containing Ethylene diamine tetra acetic acid (EDTA) and the rest was poured into a venoject tube for serum separation. All specimens were transported within first 24 hours to the Nutritional Biochemistry Laboratory of icddr,b in Dhaka for biochemical analyses of: hemoglobin [23], serum 
creatinine, alanine transaminase (ALT) [24], vitamin B12, and folic acid [19].

\subsection{Ethical Consideration}

The study objectives and its methods, its risks and benefits, as well as the rights of participants and maintenance of confidentiality of information, were described to each of the participants before their final enrollment and after signing an informed consent form.

\subsection{Statistical Analysis}

Data entry and analyses were done using Statistical Package for Social Sciences (SPSS) Windows (Version 15.2; Chicago, IL) and Epi Info (Version 6.0, USD, Stone Mountain, GA). Student's t test was performed for all continuous variables and chi-square test was applied for categorical variables where probability of (alpha) $<0.05$ was considered to be statistically significant; odds ratios and their $95 \%$ confidence intervals (CI) were also equated. In the case of non-normal distribution of data, an equivalent non-parametric test was applied. Finally, logistic regression was equated using enter method considering depression as the outcome variable (depressed $=1$; non-depressed $=0$ ) to identify explanatory variables that were associated with depression after adjusting for co-variates. The p-value cutoff of 0.1 is considered adequate to prevent residual confounding in a multivariable model $[25,26]$. In this analysis, mild and severely depressed individuals were pooled together and considered as depressed.

\section{Results}

The most common (79\%) positively scored response (yes=1) was option no. 13: "Frequently worried about future"; however, most frequent negatively (81\%) scored response (no=1) was option no. 21: "Feel of full energy". Only $9 \%$ of study participants responded to negative score $($ no=1) "Basically satisfied with life". Detailed responses of GDS were described in table 1. Median total GDS score was 11 (range; 1-28). Forty-two percent of the apparently healthy participants were mildly depressed and $17 \%$ were found to be severely depressed (Table 1).

Mean age was higher among depressed individuals compared to non-depressed. Median income (USD) was lower among depressed individuals than that of nondepressed. On the other hand, median serum folic acid level was higher among depressed individuals who were enrolled considering their optimal healthy status (Table 2). Distribution of other socio-demographic characteristics, BMI, and biomarkers were similar.

Age specific differentials among depressed individuals revealed that, mean hemoglobin and vitamin B12 were significantly lower, and folic acid was significantly higher among healthy elderly ( $\geq 60$ years) compared to that of healthy adults aged 40-59 years (Table 3 ).

In multivariate analysis, females were at 2.79 times higher risk for depression compared to males. Even healthy elderly individuals were at 2.79 times higher risk for depression compared to their healthy middle-aged counterparts (40-59 years). Individuals who ate vegetable based diet were 2.47 times more likely to be depressed. Individuals with poor monthly income expressed a 2.57 times higher chance of experiencing depression, and those with poor wealth index were 1.55 times more likely to suffer from depression compared to their counterparts after adjusting for vitamin B12, folic acid, ALT, and blood hemoglobin (Table 4).

Table 1. Distribution of GDS items of the study participants

\begin{tabular}{|c|c|c|c|c|}
\hline Indicators & $\begin{array}{l}\text { Overall } \\
\mathrm{n}=130(\%)\end{array}$ & $\begin{array}{l}\geq 60 \text { years } \\
\mathrm{n}=44(\%)\end{array}$ & $\begin{array}{l}40-59 \text { years } \\
n=86(\%)\end{array}$ & p-value \\
\hline 1. Basically satisfied with life [yes/no (1)] & $11(9)$ & $5(11)$ & $6(7)$ & 0.507 \\
\hline 2. Dropped activities and interests [yes (1)/no] & $16(12)$ & $11(25)$ & $5(6)$ & 0.009 \\
\hline 3. Feel life empty [yes (1)/no] & $27(21)$ & $8(18)$ & $19(22)$ & 0.770 \\
\hline 4. Often get bored [yes (1)/no] & $73(56)$ & $16(36)$ & $57(66)$ & 0.002 \\
\hline 5. Hopeful about future [yes/no (1)] & $24(19)$ & $9(11)$ & $15(17)$ & 0.857 \\
\hline 6. Bothered by thoughts you can't get rid of your head [yes (1)/no] & $49(38)$ & $17(39)$ & $32(37)$ & 0.974 \\
\hline 7. Good spirits most of the time [yes/no (1)] & $31(24)$ & $9(21)$ & $22(26)$ & 0.666 \\
\hline 8. Afraid something bad is going to happen to you [yes (1)/no] & $54(42)$ & $18(41)$ & $36(42)$ & 0.933 \\
\hline 9. Feel happy most of the time [yes/no (1)] & $44(34)$ & $13(30)$ & $31(36)$ & 0.585 \\
\hline 10. Often feel helpless [yes (1)/no] & $48(37)$ & $18(41)$ & $30(35)$ & 0.630 \\
\hline 11. Often get restless and fidgety [yes (1)/no] & $74(57)$ & $23(52)$ & $51(59)$ & 0.562 \\
\hline 12. Prefer to stay home rather than go out and do things [yes (1)/no] & $71(55)$ & $25(57)$ & $46(53)$ & 0.861 \\
\hline 13. Frequently worry about future [yes (1)/no] & $103(79)$ & $32(73)$ & $71(83)$ & 0.280 \\
\hline $\begin{array}{l}\text { 14. Feel you have more problems with memory than most [yes } \\
\text { (1)/no] }\end{array}$ & $61(47)$ & $27(61)$ & $34(39)$ & 0.029 \\
\hline 15. Think wonder to be alive now [yes/no (1)] & $81(62)$ & $30(68)$ & $51(59)$ & 0.425 \\
\hline 16. Feel downhearted and blue [yes (1)/no] & $71(55)$ & $29(66)$ & $42(49)$ & 0.096 \\
\hline
\end{tabular}




\begin{tabular}{|c|c|c|c|c|}
\hline Indicators & $\begin{array}{l}\text { Overall } \\
\mathrm{n}=130(\%)\end{array}$ & $\begin{array}{l}\geq 60 \text { years } \\
\mathrm{n}=44(\%)\end{array}$ & $\begin{array}{l}\text { 40-59 years } \\
\mathrm{n}=86(\%)\end{array}$ & p-value \\
\hline 17. Feel pretty worthless the way you are [yes (1)/no] & $45(35)$ & $19(43)$ & $26(30)$ & 0.202 \\
\hline 18. worry a lot about the past [yes (1)/no] & $55(42)$ & $19(43)$ & $36(42)$ & 0.965 \\
\hline 19. Find life exciting [yes/no (1)] & $44(34)$ & $17(39)$ & $27(31)$ & 0.528 \\
\hline 20. Hard to get started on new projects [yes (1)/no] & $71(55)$ & $25(57)$ & $46(53)$ & 0.861 \\
\hline 21. Feel of full energy [yes/no (1)] & $105(81)$ & $40(91)$ & $65(76)$ & 0.062 \\
\hline 22. Feel that your situation is hopeless [yes (1)/no] & $35(27)$ & $16(36)$ & $19(22)$ & 0.126 \\
\hline 23. Think most people are better off than you are [yes (1)/no] & $63(49)$ & $25(57)$ & $38(44)$ & 0.238 \\
\hline 24. Frequently get upset over little things [yes (1)/no] & $48(37)$ & $18(41)$ & $30(35)$ & 0.630 \\
\hline 25. Frequently feel like crying [yes (1)/no] & $58(45)$ & $19(43)$ & $39(45)$ & 0.961 \\
\hline 26. Trouble concentrating [yes (1)/no] & $23(18)$ & $19(43)$ & $12(45)$ & 0.000 \\
\hline 27. Enjoy getting up in the morning [yes/no (1)] & $17(13)$ & $5(11)$ & $12(14)$ & 0.889 \\
\hline 28. Prefer to avoid social occasions [yes (1)/no] & $12(9)$ & $7(16)$ & $5(6)$ & 0.104 \\
\hline 29. Easy make decisions [yes/no (1)] & $69(53)$ & $20(46)$ & $49(57)$ & 0.289 \\
\hline 30. Mind as clear as it used to be [yes/no (1)] & $49(38)$ & $20(46)$ & $29(34)$ & 0.264 \\
\hline Total score; median (range) & $11(1-28)$ & $12(2-23)$ & $11(1-28)$ & 0.271 \\
\hline Normal (0-9) & $54(42)$ & $15(34)$ & $39(45)$ & 0.296 \\
\hline Mild depress (10-19) & $54(42)$ & $20(46)$ & $34(40)$ & 0.645 \\
\hline Severe depress $(20-30)$ & $22(17)$ & $9(21)$ & $13(15)$ & 0.602 \\
\hline
\end{tabular}

Table 2. Distribution of socio-demographic characteristics, micronutrient, vitamin in depressed and non-depressed group

\begin{tabular}{lllll}
\hline Indicators & Depressed n=76 (\%) & Non-depressed $\mathbf{n = 5 4}$ (\%) & OR/mean difference ( 95\% CI) & p-value \\
\hline Consumed vegetarian based diet & $44(58)$ & $21(39)$ & $2.16(1.00,4.70)$ & 0.050 \\
Female & $47(62)$ & $24(44)$ & $2.03(0.94,4.39)$ & 0.074 \\
Age (mean \pm SD) & $59.28 \pm 11.82$ & $55.28 \pm 7.35$ & $-4.00(-7.33,-0.66)$ & 0.019 \\
Age strata ( $\geq 60$ years) & $29(38)$ & $15(28)$ & $1.60(0.71,3.66)$ & 0.296 \\
Income (US\$) median (range) & $66(6.67-333)$ & $110(20-533)$ & $(26.65-86.73)$ & $<0.001$ \\
Illiterate & $52(68)$ & $26(48)$ & $2.33(1.07,5.12)$ & 0.032 \\
Wealth index & & & \\
Poor & $10(13)$ & $15(28)$ & $0.39(0.15,1.04)$ & 0.063 \\
Low middle & $14(18)$ & $15(28)$ & $0.59(0.24,1.46)$ & 0.294 \\
Middle & $13(17)$ & $11(20)$ & $0.81(0.30,2.15)$ & 0.807 \\
Upper middle & $26(34)$ & $8(15)$ & $2.99(1.14,8.03)$ & 0.022 \\
Rich & $13(17)$ & $5(9)$ & $2.02(0.61,7.02)$ & 0.308 \\
History of smoking & $17(22)$ & $15(27)$ & $0.75(0.31,1.80)$ & 0.618 \\
Folic acid (nmol/L) median (range) & $19(3-64)$ & $15(5-87)$ & $(-6.52,1.43)$ & 0.033 \\
Vitamin B12 (pmol/L) median (range) & $137(111-601)$ & $148(111-549)$ & $(-34.97,32.68)$ & 0.799 \\
ALT (U/L) median (range) & $15(1-69)$ & $17(5-52)$ & $(-3.06,4.29)$ & 0.347 \\
Blood hemoglobin $(\mathrm{g} / \mathrm{dl})(\operatorname{mean} \pm \mathrm{SD})$ & $12.53 \pm 1.73$ & $12.87 \pm 1.41$ & $0.33(-0.28,0.96)$ & 0.283 \\
Fasting blood sugar (mean $\pm \mathrm{SD})$ & $5.84 \pm 1.86$ & $5.85 \pm 0.93$ & $0.007(-0.53,-0.55)$ & 0.979 \\
Body-mass-index (mean $\pm \mathrm{SD})$ & $19.99 \pm 3.10$ & $20.97 \pm 3.07$ & $0.97(-0.11,2.06)$ & 0.078 \\
Creatinine (micro mol/L) $(\operatorname{mean} \pm \mathrm{SD})$ & $62.73 \pm 17.36$ & $60.64 \pm 14.85$ & $-2.09(-7.85,3.67)$ & 0.474 \\
\hline
\end{tabular}

Table 3. Age specific characteristics of depressed individuals

\begin{tabular}{lllll}
\hline Indicators & $\mathbf{6 0}$ and above $\mathbf{n}=\mathbf{2 9}(\mathbf{\%})$ & $\mathbf{4 0 - 5 9}$ years $\mathbf{n}=\mathbf{4 7}$ (\%) & OR/mean difference $(\mathbf{9 5 \%} \mathbf{C I})$ & $\mathbf{p}$-value \\
\hline Consumed vegetable based diet & $18(62)$ & $26(55)$ & $1.32(0.46,3.79)$ & 0.733 \\
Female & $18(62)$ & $29(62)$ & $1.02(0.35,2.94)$ & 0.832 \\
Income (US\$) median (range) & $53(7-267)$ & $80(8-333)$ & $(-28.49,37.37)$ & 0.387 \\
Illiterate & $23(79)$ & $29(62)$ & $2.38(0.73,8.04)$ & 0.176 \\
History of smoking & $7(24)$ & $10(21)$ & $1.18(0.34,4.02)$ & 0.994 \\
Folic acid (nmol/L) median (range) & $26(11-49)$ & $16(4-65)$ & $(-7.80,0.47)$ & $<0.001$ \\
Vitamin B12 (pmol/L) median (range) & $116(111-341)$ & $180(111-601)$ & $(10.49,79.12)$ & 0.039 \\
ALT (U/L) median (range) & $9(2-36)$ & $18(6-69)$ & $(3.48,10.73)$ & 0.000 \\
Blood hemoglobin (g/dl) (mean $\pm \mathrm{SD})$ & $11.89 \pm 1.73$ & $12.96 \pm 1.61$ & $1.06(0.26,1.87)$ & 0.011 \\
\hline
\end{tabular}


Table 4. Multiple regression analysis for socio-demographic characteristics, vitamin and micronutrient among depressed and nondepressed individuals

\begin{tabular}{lll}
\hline Indicators & OR $(\mathbf{9 5 \%} \mathbf{C I})$ & p-value \\
\hline Age & $2.79(0.94,8.33)$ & 0.064 \\
Sex & $2.79(0.94,8.26)$ & 0.064 \\
Consumed vegetable based diet & $2.47(0.85,7.15)$ & 0.094 \\
Income & $2.57(0.94,7.01)$ & 0.066 \\
Wealth index & $1.55(1.07,2.25)$ & 0.018 \\
Folic acid $(\mathrm{nmol} / \mathrm{L})$ & $0.99(0.95,1.04)$ & 0.906 \\
Vitamin B12 (pmol/L) & $1.00(0.99,1.01)$ & 0.072 \\
ALT (U/L) & $1.02(0.97,1.08)$ & 0.318 \\
Blood hemoglobin $(\mathrm{g} / \mathrm{dl})$ & $0.95(0.69,1.32)$ & 0.791 \\
\hline
\end{tabular}

Reference categories: Dependent variable: non-depressed; Independent variable: 40-59 years, male, non-vegetarian, more than median income, rich wealth index.

\section{Discussion}

Rural elderly were more prone to suffer from depression due to family disharmony, financial crisis, or physical and mental disability towards responsibilities [27]. Although depression among the elderly has been reported elsewhere $[3,4]$, observations among apparently healthy individuals from rural Bangladesh, using a simple GDS tool may be considered as a novel approach that might have significant public health implications. The 30 -item scale not only indicates the proper situation, but also helps to determine the in-depth status that leads to depression. For example, at least $9 \%$ of the healthy study individuals were not satisfied with their life, $21 \%$ indicated "Feel life empty", 56\% "Often get bored," and 37\% "Often feel helpless". In fact, rural individuals and their family often lack economic solvency, frequently struggle for day-to-day wage earning, and commonly depend on products from their agriculture farms including harvesting of their staple foods [28]. Moreover, they often suffer from interruptions in their wage earnings due to seasonal heavy monsoon and flash flooding, which might encourage them to find alternative sources of daily wage earning resulting in migration to large cities. Due to inability to travel or perform daily activities, elderly often become a burden to their family, especially in insolvent/poverty-stricken families in rural Bangladesh.

Depression may differ with individual's sex. For example in the present study, rural healthy females were more depressed than males; studies also reported a high prevalence of depression among females [10,29]. There are several factors that might explain our observation such as: death of spouse, socio-cultural barriers, and lack of participation in income generating activities during their life span [30-33]. However, the present study did not aim to determine the associated factors of high depression among females and thus, urges for further studies. Moreover, physiological changes, mainly early onset of menopause or post-menopause, might also influence women to become more depressed than men [1,34]. As our study participants were aged 40 years and more, most of the female participants might have been either in post-menopausal state or close to start of menopause.

On the other hand, poor earnings and poor socioeconomic background was directly associated with depression among individuals. Bangladesh is a poor, largely rural country where vast majority of the total population is still below the national poverty line [10]; although the country has recently observed sustained impressive economic growth [35]. Gross family income not only impacts daily life style, but also influences behavior. It also influences quality food consumption; often compelling poor individuals to settle for less micronutrient or unhygienic food. For example, in the present study, depressed individuals consumed only vegetable-based diets that are both inexpensive and easily available; and such consumption found to have direct correlation with depression. These foods grossly lack vitamins such as vitamin B12 which is one of the essential components for the regeneration of nervous tissue [23]. Deficiency of such vitamins may have an impact to influence an individual's depressive state. Moreover, $10-15 \%$ of the elderly population from developing countries suffer from vitamin B12 deficiency due to low consumption of animal-source foods [19]. In contrast to that, serum folate was grossly higher among the depressed individuals only in the univariate model; although low folate level was reported among depressed individuals. Folate has emerged as an important nutrient in several key conditions of concern to the elderly $[15,16]$.

\section{Strengths and Weaknesses}

We were careful in identifying the healthy study population to avoid influence of chronic diseases on depression among the rural population. Thus sample size was smaller, which might have resulted in many important indicators not to be associated with depression at $<0.05$ level and desire for a prospect study with large sample size to consolidate present observations. However, the study findings in many respects were comparable with studies from other context.

\section{Conclusion}

Healthy elderly individuals from rural community were more depressed than middle-aged adults, and females with poor socio-economic status were at higher risk for depression than males. The findings may have significant impact on policy implications; especially formulation of strategies for the well being of rural depressed individuals that include social mobilization, health assurance, and nutritional supplementation. 


\section{Acknowledgements}

This research study was funded by Government of the People's Republic of Bangladesh through IHP-HNPRP, grant number GR/00410. icddr,b acknowledges with gratitude the commitment of Government of the People's Republic of Bangladesh to its research efforts. Our earnest thanks go to Kumudini Women's Medical College and Hospital for providing us the support to conduct the study. We are also thankful to Bidduth Sarkar for screening and specimen collection.

\section{References}

[1] Sharp LK, Lipsky MS: Screening for depression across the lifespan: a review of measures for use in primary care settings. Am Fam Physician 2002, 66:1001-8.

[2] Baiyewu O, Smith-Gamble V, Lane KA, Gureje O, Gao S, Ogunniyi A, Unverzagt FW, Hall KS, Hendrie HC: Prevalence estimates of depression in elderly communitydwelling African Americans in Indianapolis and Yoruba in Ibadan, Nigeria. Int Psychogeriatr 2007, 19:679-89.

[3] Vishal J, Bansal RK, Swati P, Bimal T: A study of depression among aged in Surat city. National Journal of Community Medicine 2010, 1.

[4] Wang JK, Su TP, Chou P: Sex differences in prevalence and risk indicators of geriatric depression: the Shih-Pai community-based survey. J Formos Med Assoc 2010, 109:345-53.

[5] Wasylenki D: Depression in the elderly. Can Med Assoc J 1980, 122: 525-32, 40.

[6] Alexopoulos SG: Depression in the elderly. The Lancet 2005, 365:1961-70.

[7] Demura S, Sato S: Relationships between depression, lifestyle and quality of life in the community dwelling elderly: a comparison between gender and age groups. J Physiol Anthropol Appl Human Sci 2003, 22:159-66.

[8] Levkoff ES, Macarthur WL, Bucknall J: Elderly mental health in the developing world. Social science and Medicine 1995, 41: 983-1003.

[9] Ibrahim N, Din NC, Ahmad M, Ghazali SE, Said Z, Shahar S, Ghazali AR, Razali R: Relationships between social support and depression, and quality of life of the elderly in a rural community in Malaysia. Asia Pac Psychiatry 2013, 5 Suppl 1:59-66.

[10] Taqui AM, Itrat A, Qidwai W, Qadri Z: Depression in the elderly: does family system play a role? A cross-sectional study. BMC Psychiatry 2007, 7:57.

[11] Biswas P, Kabir ZN, Nilsson J, Zaman S: Dynamics of Health Care Seeking Behaviour of Elderly People in Rural Bangladesh. International Journal of Ageing and Later Life 2006, 1:69-89.

[12] Russell DW, Cutrona CE: Social support, stress, and depressive symptoms among the elderly: test of a process model. Psychol Aging 1991, 6:190-201.
[13] Oxman TE, Berkman LF, Kasl S, Jr DF, Barrett J: Social Support and Depressive Symptoms in the Elderly. American Journal of Epidemiology 1991, 135:356-68.

[14] Melanson KJ: Relationships of Nutrition With Depression and Anxiety. American Journal of Lifestyle Medicine 2007, $1: 171-4$.

[15] D'Anci KE, Rosenberg IH: Folate and brain function in the elderly. Curr Opin Clin Nutr Metab Care 2004, 7:659-64.

[16] Reynolds EH: Folic acid, ageing, depression, and dementia. BMJ 2002, 324:1512-5.

[17] Nguyen PH, Grajeda R, Melgar P, Marcinkevage J, DiGirolamo AM, Flores R, Martorell R: Micronutrient supplementation may reduce symptoms of depression in Guatemalan women. Arch Latinoam Nutr 2009, 59:278-86.

[18] Nasrin N, Asaduzzaman M, Imam A-HKM, Mowla R, Rizwan F, Monjur F: Common geriatric disorders and their management in selected hospitas of Bangladesh. International Journal of Pharmaceutical Sciences Review and Research 2012, 13.

[19] Das SK, Faruque ASG, Ahmed S, Mamun AA, Raqib R, Roy AK, Chisti MJ, Ahmed T, Salam MA: Nutritional and Micronutrient Status of Elderly People Living in a Rural Community of Bangladesh. Journal of Gerontology \& Geriatric 2012, 1:107.

[20] Yesavage JA, Brink TL, Rose TL, Lum O, Huang V, Adey M, Leirer VO: Development and validation of a geriatric depression screening scale: a preliminary report. J Psychiatr Res 1982, 17:37-49.

[21] Koehler M, Rabinowitz T, Hirdes J, Stones M, Carpenter GI, Fries BE, Morris JN, Jones RN: Measuring depression in nursing home residents with the MDS and GDS: an observational psychometric study. BMC Geriatr 2005, 5:1.

[22] Ganguly M, Dube S, Johnston Jm, Pandav R, Chandra V, Dodge HH: Depressive symptoms, cognitive impairement and functional impairement in a rural elderly population in India. International Journal of Geriatric Psychiatry 1999, 14:807-20.

[23] Farzana FD, Ahmed S, Ferdous F, Vanderlee L, Khan HS, Roy KA, Chisti JM, Faruque ASG, Das SK: Biochemical and dietary indicators among vegetarians and nonvegetarians: findings from a cross sectional study in rural Bangladesh. International Journal of Nutrition and Food Sciences 2013, 2:130-6.

[24] Das SK, Faruque ASG, Chisti MJ, Ahmed S, Abdullah AM, Chowdhury AK, Ahmed T, Salam AM: Nutrition and Lipid Profile in General Population and Vegetarian Individuals Living in Rural Bangladesh. Journal of Obesity \& Weight Loss 2012, 2:123.

[25] Budtz-Jorgensen E, Keiding N, Grandjean P, Weihe P: Confounder selection in environmental epidemiology: assessment of health effects of prenatal mercury exposure. Ann Epidemiol 2007, 17:27-35.

[26] Maldonado G, Greenland S: Simulation study of confounder-selection strategies. Am J Epidemiol 1993, 138:923- 36.

[27] Karel MJ: Aging and depression: vulnerability and stress across adulthood. Clin Psychol Rev 1997, 17:847-79. 
[28] Agarwalab B: Social security and the family: Coping with seasonality and calamity in rural India. The Journal of Peasant Studies 2008, 17:341-412.

[29] Habib F, Roomi KA, Al-Haddad MK: Risk factors associated with depression among Bahraini elderly in a primary healthcare setting. Journal of the Bahrain Medical Society 2013, 24.

[30] Hossain RM: Demography of Aging and related problems in Bangladesh. The social Sciences 2006, 1:154-7.

[31] Nasreen HE, Kabir ZN, Forsell Y, Edhborg M: Prevalence and associated factors of depressive and anxiety symptoms during pregnancy: a population based study in rural Bangladesh. BMC Womens Health 2011, 11:22.
[32] Tareque MI, Begum S: Gender difference in disability free life expectancy at old ages in Bangladesh. Journal of Aging Health 2013.

[33] Barcelos-Ferreira R, Yoshio Nakano E, Steffens DC, Bottino $\mathrm{CM}$ : Quality of life and physical activity associated to lower prevalence of depression in community-dwelling elderly subjects from Sao Paulo. J Affect Disord 2013, 150:616-22.

[34] Vermeulen A: Environment, human reproduction, menopause, and andropause. Environ Health Perspect 1993, 101 Suppl 2:91-100.

[35] Bloom DE, Williamson JG: Demographic Transitions and Economic Miracles in Emerging Asia. The World Bank Economic Review 2013, 12:419-55. 